Article

\title{
Understanding Child Outcomes within a Multiple Risk Model: Examining Parental Incarceration
}

\author{
Melody L. Hyppolite \\ Department of Social Work, Ramapo College of New Jersey, 505 Ramapo Valley Rd., Mahwah, NJ 07430, USA; \\ mhyppoli@ramapo.edu
}

Received: 6 May 2017; Accepted: 20 July 2017; Published: 27 July 2017

\begin{abstract}
The risks in children's lives often co-occur and overlap in time. The purpose of this study is to examine the impact of parental incarceration within a multiple risk model that allows for the control of other prominent risk factors in a child's life. The impact of four primary parental risk factors (parental mental illness, parental substance use, parental mental illness, and poverty) on seven child outcomes (school failure, criminal behaviors, being arrested, behavioral difficulties, emotional difficulties, alcohol use, and drug use) was examined. The study utilizes a statistical analysis that is rarely seen in social work research and helps the researcher to better understand the individual contributions of various risk factors. The accumulation of multiple risk factors in a child's life was found to significantly increase the likelihood that several negative outcomes would occur. The research, however, suggests further that this is an over simplification of the phenomenon and that specific risk factors are more likely to contribute to specific child outcomes.
\end{abstract}

Keywords: parental incarceration; multiple risk model; child outcomes; parental mental illness; parental substance use; poverty; multivariate probit regression

\section{Introduction}

Children with incarcerated parents constitute a growing population within our communities-there are an estimated two million children with a parent currently incarcerated and that number does not include children whose parents have been previously incarcerated and released or those whose parents are under some community supervision such as probation or parole (La Vigne et al. 2008; Graham and Harris 2013). Researchers have documented the negative outcomes that many of these children face, including future substance use, academic underachievement, poverty, and future criminality (Dallaire 2007; Poehlmann et al. 2008; Travis et al. 2003; Kjellstrand and Eddy 2011). It would be difficult to argue that the incarceration of a parent does not have a profound impact on those children left behind; however, there is limited research in the literature that parses out those effects of parental incarceration from other traumatic and stressful circumstances that also generally characterize the lives of these children (Travis and Waul 2003; Nichols et al. 2016).

Society often forgets that, when incarcerated men or women enter prison, they often leave children and families behind. These innocent bystanders to their parents' crimes carry heavy burdens of grief and confusion and are at high risk of following in the criminal footsteps of their parent(s) (La Vigne et al. 2008; Moses 1995). Punitive attitudes toward crime have overlooked or ignored the impact that the incarceration boom in the United States has heaped upon some of the most vulnerable in our country.

While having an incarcerated parent creates a unique set of risks, such as stigma, shame, and depleted resources (Johnson 2009), it is important to also consider the impact of multiple, pre-incarceration, risk factors. Multiple studies have examined the impact of incarceration on families (Poehlmann 2005; Wakefield 2007; Dallaire 2007; Murray et al. 2012; Aaron and Dallaire 2010), but most 
existing studies have not been able to separate the causal effects of incarceration from the effects of other risk factors that were already present in a child's life. These risk factors include parental substance use, parental mental illness, and poverty. Johnson and Easterling (2012) discuss the "null hypothesis" theory that states that parental incarceration has no effect of child outcomes or development and those previous studies failed to account for various risks in children's high-risk ecosystems. It is difficult to accept that parental incarceration has no effect, but it is important to consider that for many children, other environmental factors had already placed them at an increased risk of negative outcomes long before their parents were incarcerated (Johnson and Waldfogel 2004).

Due to a lack of longitudinal data, it is very difficult for researchers to separate the effects of individual risk from other risk factors. This study proposes a comparison between matched samples of at-risk children, some of whom experience parental incarceration and some who do not. Data collected by the Children at Risk program in five communities (Austin, TX, USA; Bridgeport, CT, USA; Memphis, TN, USA; Seattle, WA, USA; and Savanna, GA, USA) and publically available through the Inter-University Consortium for Political and Social Research (ICPSR) consist of baseline and follow-up data for children identified to be at risk due to residing in neighborhoods characterized by poverty, delinquency, drug problems, and crime (Harrell et al. 1998). Children in the study range in age from 10 to 13 years of age. The aim of the current study is to examine the outcomes for at-risk children who experience parental incarceration, as defined through caregiver report as having a history of serving time in jail or prison, compared to those who do not and determine whether documented negative outcomes are more or less likely to be due to parental incarceration in the presence of other personal and environmental risk factors such as poverty, parental substance use, and mental illness.

\subsection{Children with an Incarcerated Parent}

The removal of a parent due to a period of incarceration creates unique and individual challenges and stressors for children that often go unnoticed or are underestimated by others (La Vigne et al. 2008). These challenges include stigma and shame, uncertainty and instability, poverty due to incarceration, and the challenges of reunification (La Vigne et al. 2008; Miller 2006; Moses 1995; Travis et al. 2003; Hagen and Myers 2003).

Sixty-two percent of women incarcerated in state prisons report being mothers and are more likely to have been living with their children prior to their imprisonment (U.S. Department of Justice 2010). These mothers tend to be single and uneducated and are much more likely to be incarcerated due to drug crimes (Hyppolite 2017). Additionally, incarcerated mothers have a disproportionate incidence of mental illness and substance use (Poehlmann 2005). These characteristics have been shown to contribute to developmental issues, attachment difficulties, difficulty empathizing, and other negative behaviors (Greenberg 2006).

Approximately half of the men incarcerated in the US are fathers, and they were typically not the primary caregiver for their children before their imprisonment (Kinner et al. 2007). The impact of imprisoning America's fathers is often underestimated, and much of the research focuses on the effects of maternal incarceration; however, paternal incarceration also carries severe and negative consequences for children and families (Roy and Dyson 2005).

During a period of incarceration, most families experience financial loss. The most significant loss occurs when the imprisoned family member was a contributing part of the family prior to incarceration, but many families are also burdened by the added expenses of providing money for toiletries, food, health care co-pays and collect phone calls to their family member in prison (Bloom and Steinhart 1993; Mackintosh et al. 2006). If children go into the care of other family members or grandparents, often already stretched resources are further stretched to meet the costs of raising the children (La Vigne et al. 2008; Smith et al. 2004).

Evidence supports the tradition that most fathers provided financial support to their children, either formal or informal, before being incarcerated. This loss of income can create a significant financial burden for those left caring for the children. The loss of a mother's income, however, can 
have even greater economic consequences. Most mothers who go to prison are single women who were the sole source of support for their children. Many children experience even greater levels of poverty after a parent goes to prison because they are often placed in the homes of impoverished family members. The circumstance of these family members is further burdened by the addition to their families and the difficulties created by social policies that make it hard for grandparents and other relative caregivers to access public assistance programs such as Temporary Assistance for Needy Families (TANF) (Miller 2006).

In addition to financial burdens, there is often a high emotional toll taken on the children of prisoners. They often experience a tremendous sense of loss as relationships are disrupted. Break-ups and divorce are common, leaving families broken, or if relationships between the mother and father were already negative, they are further exacerbated (Hairston and Oliver 2006, 2007; Nurse 2002). Incarcerated mothers report that separation from their children is one of the most difficult, if not the most difficult, aspects of incarceration. Guilt and shame take a heavy toll as mothers and fathers struggle with the knowledge that their children's lives have been severely disrupted due to their choices and behaviors (Golden 2005; Moe and Ferraro 2006). The ways in which parents and caregivers cope with this stress can greatly impact the children. Parents, both at home and in prison, may be unable to provide the nurturing and guidance that children need as they struggle to cope with financial and social stressors (Hairston 1995).

Separation from a parent will always result in stress, sadness, and other negative emotions. Research shows that it matters little whether that separation is caused by death, divorce, or incarceration (La Vigne et al. 2008). When a parent dies, however, it is final, and a child can cope with the loss and move on. When a parent is separated due to incarceration, it is ambiguous and often difficult for children to understand. Their parents are alive, yet absent from their lives. Children of incarcerated parents are likely to feel ashamed and fear rejection from others in their environment if it is discovered. Additionally troublesome is when family members reject the children because of anger and resentment that they harbor toward the children's parents (Arditti et al. 2003). In an attempt to avoid rejection, children will often withdraw from meaningful relationships. Their egocentric viewpoints can further complicate the problem when they blame themselves for their parents' criminal behaviors and begin to display symptoms of depression or other emotional/behavioral disorders (Hairston 2007; Miller 2006).

\subsection{Role of Other Risk Factors}

Much of the existing research fails to separate the risk posed by traumatic and stressful circumstances from those posed by losing a parent to incarceration. The pathways of risk are multi-faceted, overlapping, and reoccurring (Greenberg et al. 1999). Risk factors are not linear and do not occur independently of each other. Rather, they often occur simultaneously, and the complexity of risk makes it extremely difficult to tease out the effects of any one risk factor. Additionally, the effects of risk vary greatly and depend on child and family strengths, support systems, services available and the specific combination of risk factors that are as unique as every child and family across this country (Hyppolite 2017; Johnson and Waldfogel 2004; Johnson 2009; Nichols et al. 2016).

\subsubsection{Poverty}

Approximately 14 million children in the US live in households that fail to exceed the poverty threshold. An additional one-fifth of children live in households that make no more than twice the federal poverty level. The impact of poverty can be profound in the lives of these children by creating additional risks that include malnutrition, inadequately resourced schools, instability, environmental injustices, and homelessness (LaMont 2014). Many of these families fall into a category that includes those making more than the poverty guidelines allow, but not enough to meet the financial needs of the family. This is especially true for families with children with medical, mental, or development disabilities. Because measures of poverty have remained relatively unchanged for several decades, 
the working poor make up a growing percentage of the American population (Roll and East 2014). Poor children suffer higher incidences of developmental problems, adverse health conditions, and other negative outcomes than non-poor children. Specific outcome areas that are negatively impacted include physical health, cognitive ability, school achievement, and emotional and behavioral outcomes (Brooks-Gunn and Duncan 1997).

\subsubsection{Parental Substance Use}

Many of the studies examining parental substance use show a broad array of differences between children raised by parents who use substances and parents who do not. Children exposed to parental substance use exhibit a myriad of problems at a higher rate than those who are not, including poor developmental outcomes, behavioral problems, delinquency, substance use and they are more likely to experience abuse and neglect (Finkelstein et al. 2005; Johnson and Waldfogel 2004; Yule et al. 2013). Additionally, these children are shown to be at a higher risk of attachment difficulties, poor emotional and behavioral development, poor health outcomes and poverty. A possible explanation for this is that substance use impeded parental psychological functioning and parenting competence (Osborne and Berger 2009).

\subsubsection{Parental Mental Illness}

Parents with a mental illness struggle with common parenting behaviors including the use of appropriate discipline strategies, communication skills (Oyersman et al. 2000), and forming appropriate attachments (Hill 1996). Mentally ill parents function at overall lower levels than non-mentally ill parents (Oyersman et al. 2002; Goelman et al. 2014). Many times the symptoms are so severe that maintaining employment is impossible and many of those suffering from mental illness are forced to live in poverty and rely on public assistance to meet the needs of their families (Harpaz-Rotem et al. 2006; Mowbray et al. 2000; Oates 1997).

\subsection{A Multiple Risk Model}

Each of the above risks may negatively affect the child. When more than one risk is observed the effect of an individual risk cannot be correctly estimated without controlling for the presence of the other ones. Models of development often place human development within a complex system of interactions between individuals and their environments. A transactional model, however, takes the process of development one step further and asserts that development occurs when there are continuous and dynamic interactions occurring between children and the social contexts in which they are immersed (Sameroff et al. 1998). In all models, the effects of individual and environmental factors are important. Those factors that adversely affect development are risk factors, while those that promote development or protect against adversity are protective factors (Johnson and Waldfogel 2004).

Multiple risk models take into account the effects of various risks within children's lives and the environments that impact their overall development. The greater the number of risk factors in a child's life, the more likely that child is to face adversity or experience negative effects developmentally. Researchers have explored the concept of multiple risks and have determined that there is a relationship between the number of parental and ecological risk factors in a child's life and child outcomes such as cognitive performance (Sameroff et al. 1998), social competence (Furstenberg et al. 1999), and behavioral disorders (Williams et al. 1990).

In the current study, a model of multiple risks is being tested to determine whether parental incarceration or the risks that exist before a period of parental incarceration, or outside of parental incarceration, contribute more significantly to negative child outcomes. The pre-parental incarceration risks addressed by the model include poverty, parental mental illness, and parental substance use.

The multiple risk model presented here is designed to move throughout a child's life. The model begins with the inherent risks when children are products of high-risk pregnancies or high-risk births. As children progress through life, symbolized by the arrow pointing right in Figure 1, they can be 
impacted by other life variables that are of interest in this research: poverty, parental mental illness, and parental substance use. Many of these risks are present in children's lives before parents are ever arrested or imprisoned. Once a parent is incarcerated a unique set of risk factors is introduced to the child that may further impact child outcomes. It is important to note that although the model appears to be linear, the risk factors presented do not often occur in a linear fashion in a child's life. Many times, they all occur at once, or they are present and addressed, then return later in a child's life.

Multiple risk models have been tested in the literature, but the important contribution of this study is the addition of parental incarceration as a risk factor. Parental incarceration has been inadequately studied as it relates to child outcomes and the vast majority of research on the subject does not examine the risk within the context of other risk factors in children's lives. If a researcher is interested in examining any one risk factor but fails to account for other relevant risks or those correlated to included risks, then the estimation of the effect of the included risks will not be correct and could contain bias. By estimating the model to include relevant risks, the likelihood of avoiding error is significantly increased and helps the researcher to better understand the true impact of risk.

The current study utilizes a statistical method, multivariate probit regression, which has rarely been used in the field of social work and has not been applied to a multiple risk model that examines the risks identified in this study. The important and novel contribution of this study is the addition of a critical parental risk factor that has been inadequately studied as it relates to other risks in a child's life and the subsequent child outcomes-parental incarceration.

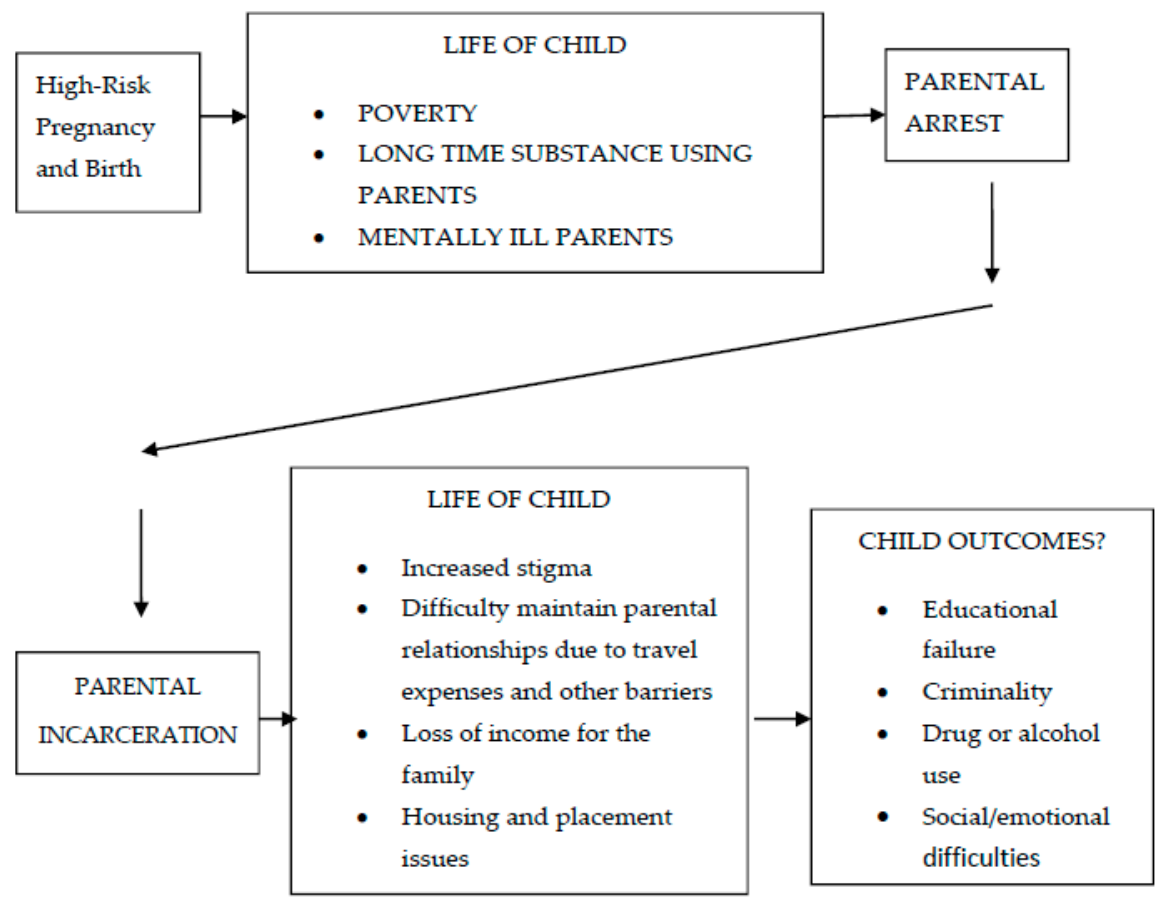

Figure 1. A Multiple Risk Model-poverty, parental substance use, parental mental illness, and parental incarceration.

\subsection{Child Outcomes}

Examining possible child outcomes is important for a strong understanding of the impact that the risk factors already discussed often have on child behaviors, emotions, and life choices. For the purposes of this study, seven outcomes will be examined: (a) school failure; (b) emotional difficulties; (c) behavioral difficulties; (d) criminal behaviors; (e) being arrested; (f) alcohol use; and (g) drug use. 


\subsubsection{School failure}

Educational success has been linked to positive outcomes throughout life and yet children face multiple risks that put their educational attainment in jeopardy. Parental involvement has been identified as an essential ingredient to improved student behavior and academic achievement (Cooper and Jordan 2003; Hill and Taylor 2004; Lareau 1996; Cho 2010). Having a parent closely involved with school activities allows for consistent set of rules to be communicated to a child across both home and school settings (Hill and Taylor 2004) and allows parents to be more involved and able to provided academic assistance to their children (Lareau 1996). Having a parent that is abusing substances, suffering from severe mental illness, or absent due to incarceration would severely limit the capacity for and scope of parental involvement.

\subsubsection{Emotional/Behavioral Difficulties}

Many risk factors have been shown to contribute to negative health and psychological outcomes in childhood, adolescence and into adulthood. Parental depressive disorder and other forms of psychopathology have been established as factors that raise the risk of mental disorders in children (Davenport et al. 1984; Downey and Coyne 1990; Gutijahr 2007). Other risk factors identified as contributors to childhood mental health disorders include substance abuse and chaotic family environments (Pirkola et al. 2005).

\subsubsection{Criminal Behavior/Being Arrested}

Adult criminality has significant roots to childhood experiences. Criminal justice research has long asserted that problem behaviors during childhood are indicative of problem behaviors as adults. Researchers have documented that aggressive behaviors in childhood often predict aggressive behaviors in adolescence and consequently adulthood (Trembley et al. 2003). Robins (1978) found that "adult antisocial behavior virtually requires childhood antisocial behavior" (p. 611). Similarly, criminal behavior in adolescence has been linked to other negative risk factors in children's lives such as poverty, parental substance use, and parental mental illness.

\subsubsection{Drug and Alcohol Use}

Deficits in parental support and poor parental control have been identified as risks for adolescent substance use (Chassin et al. 1996). Parent drug use, parental mental illness, and parental incarceration can be significant barriers to a parent offering sufficient support to their children or being able to place appropriate controls on them. Children of alcoholics have been found to be at an elevated risk for problem alcohol use in adolescence and alcohol dependence in adulthood (Colder et al. 1997).

\subsection{Multivariate Probit Regression}

This study utilizes dichotomous dependent variables that take the value of 1 if the variable is present and 0 if it is not. In order to estimate the probability of the likelihood of the occurrence of each outcome a multivariate probit regression can be used. In situations where the dependent variables are not believed to be related, it would be appropriate to use separate univariate probit models. However, in the current study, the impact of multiple risk factors on child outcomes, which are likely to be correlated, are being examined. Due to that correlation, a multivariate test would be more appropriate (Long 1997). As a review of the literature suggests, negative child outcomes often manifest in the form of behavioral problems at home, at school, or in the community. It is likely that difficulties at home will lead to difficulties at school and children's decisions to use drugs or engage in criminal behavior that will impact their interactions with their families and their school performance. Multivariate probit models allow for the simultaneous examination of multiple dependent variables when the variables are believed to be related to one another. Table 1 illustrates that many of the dependent variables are highly correlated. 
Table 1. Correlations among Dependent Variables (Outcomes).

\begin{tabular}{|c|c|c|c|c|c|c|c|}
\hline \multicolumn{8}{|c|}{ Correlation Table-Dependent Variables } \\
\hline & $\begin{array}{l}\text { School } \\
\text { Failure }\end{array}$ & $\begin{array}{l}\text { Criminal } \\
\text { Behavior }\end{array}$ & Arrested & $\begin{array}{l}\text { Behavioral } \\
\text { Difficulty }\end{array}$ & $\begin{array}{l}\text { Emotional } \\
\text { Difficulty }\end{array}$ & Alcohol Use & Drug Use \\
\hline School Failure & $1.0000^{* * *}$ & & & & & & \\
\hline Criminal Behavior & $0.1052 * * *$ & 1.0000 & & & & & \\
\hline Arrested & $0.1046^{+}$ & $0.2203^{* * *}$ & 1.0000 & & & & \\
\hline Behavior Difficulty & $0.0496^{* * *}$ & $0.2895 * * *$ & $0.1485^{* * *}$ & 1.0000 & & & \\
\hline Emotional Difficulty & $0.1276^{* * *}$ & $0.0801^{* * *}$ & 0.0069 & $0.1119^{* * *}$ & 1.0000 & & \\
\hline Alcohol Use & $0.0718^{* *}$ & $0.3520 * * *$ & $0.1877 * * *$ & $0.2307^{* * *}$ & $0.0674^{* *}$ & 1.0000 & \\
\hline Drug Use & $0.0653 *$ & $0.3246^{* * *}$ & $0.1438^{* * *}$ & $0.1988^{* * *}$ & $0.0812 * * *$ & $0.7213^{* * *}$ & 1.0000 \\
\hline
\end{tabular}

Additionally, multivariate probit models are more flexible than logit models and impose fewer restrictions on the analysis. The normal correlation distribution can be assumed and this allows for flexible modeling of the correlation structure and a straightforward interpretation of the parameters (Chib and Greenberg 1998). The analysis has never become popular due to the intensive nature of the calculations involved in estimating the model. Several statistical packages however, including STATA 11 , now allow for these types of analyses making the test more accessible to researchers.

Muthen (1989), a well know statistician within psychometrics, uses the probit model to address multiple research questions including an analysis of symptom data for anxiety and depression. Downey et al. (2009) used the probit model to examine the end-of-life priorities of terminally ill patients and their intimate associates. Health service utilization and insurance coverage were also analyzed, by another set of researchers, and the probit analysis provided a way for assessing the relationship between insurance coverage and service utilization simultaneously for all five heath care services being examined (Gibbons and Wilcox-Gok 1998).

\section{Methods}

\subsection{Research Design}

Two primary research questions were addressed by the study.

Research Question 1: To what degree do parental risk factors influence child outcomes?

Hypothesis 1. The presence of multiple parental risk factors will increase the likelihood that children experience negative child outcomes.

Research Question 2: Are child outcomes more significantly linked to any one parental risk factor over another?

Hypothesis 2. Specific child outcomes are more significantly linked to specific risk factors.

The study utilizes a pre-experimental post-test only non-equivalent group design and allows for the consideration of multiple risk factors to determine the individual and combined impact on key child outcomes. The independent variables examined include parental incarceration, parental substance use, parental mental illness, and poverty.

\subsection{Sample: The Children at Risk Program (CAR)}

The Children at Risk Program was a program designed to prevent drug-use, delinquency, and other problem behaviors among children living within specific neighborhoods that were identified as severely distressed (Harrell et al. 1998). The neighborhoods were located in five US cities: Austin, TX; Bridgeport, CT; Memphis, TN; Seattle, WA; and Savannah, GA. For the original program evaluation, three groups were created-experimental, control, and quasi-experimental. Children in the experimental and 
control groups all lived in the target neighborhoods and met the other admission criteria outlined in the study. In the original study, children were randomly selected into each group, and random assignment occurred at the family level so that sibling groups would be in the same study group. The quasi-experimental group was made up of a matched sample of children who met the CAR eligibility requirements, but who lived in separate neighborhoods that were determined to be equally distressed as the study neighborhoods. These children were not eligible to receive the intervention. The researchers created this group to control for other variables in the environment (e.g., court and school programs) that may also influence child outcomes (Harrell et al. 1998).

The total sample was comprised of 865 children when the control, experimental, and quasi groups were combined. For this analysis, only the baseline data will be examined as the impact of the intervention is not important to the current research questions.

Due to the use of a secondary dataset, the current sample of children cannot be considered to be representative of the general population. All children were identified by the original researchers to be high risk to be eligible to participate in the intervention originally being tested. The prevalence of each of the risk factors is higher in this sample than in the general population. Nationally, $2 \%$ of children have an incarcerated parent (Johnson and Waldfogel 2004), the poverty rate in the United States is approximately $13 \%$ (Corcoran and Chaudry 1997), approximately $6 \%$ of children have a parent addicted to substances (Grant 2000) and mentally ill parents are just as likely as those who are not mentally ill to parent at least one child (Ackerson 2003). In the current sample, 13\% of children have a mentally ill parent, $11 \%$ have a parent that uses substances, $17 \%$ have an incarcerated parent, and $70 \%$ live in poverty. All of these percentages represent a higher prevalence of risk factors among this sample than in the general population of children.

\subsection{Measures and Constructs}

\subsubsection{Independent Variables (Risks)}

There are three ways to compare statistical risk models: (1) examine each risk separately; (2) group the risks together into larger risk factors; and (3) create a risk index score (Burchinal et al. 2000). In the current study, examining each risk separately would mean that 47 individual risk variables would have to be entered into the regression equation. There are two reasons why this is problematic. First, a high number of variables require a large sample size to make the results valid. Second, a high degree of overlap among the variables is anticipated, as well as strong correlations among the variables that make the results invalid (Long 1997).

The second method, grouping risks together in larger risk factors, allows the researcher to determine overall risk within several risk groups (factors) and the resulting score can then be used in the regression equation, thereby eliminating the issue of having multiple variables in one equation (Burchinal et al. 2000). Principal component analysis is a method for reducing data that allows a coefficient to be assigned to each risk factor and a new score is generated based on a statistical determination of which components are more important, or principal. Unfortunately, the use of principal component analysis is not possible with the current dataset due to missing values. In principal component analysis, any variable that has even one missing value will be given an overall score of missing. Therefore, the variables that make up the risk factors discussed below were qualitatively chosen based on my understanding of the literature and my determination of which variables were most critical to be included in the risk factor.

In the current analysis, four risk factors were entered into the probit regression model in order to determine the probability of several child outcomes when these primary risks were controlled for. The multivariate probit regression allows for the simultaneous modeling of several dichotomous variables.

Parental mental illness was measured by caregiver question C42G (received counseling or therapy?). It was dichotomous (yes/no) and was not transformed for the purposes of analysis. 
Parental substance use is measured using caregiver questions C42C (drug or alcohol counseling or treatment?), CB7 (used drugs to get high?), and CB15 (other members of the household used drug?). Variables were dichotomous (yes/no) and were not transformed for purposes of analysis. A new variable (cdrug) was generated by coding each caregiver as engaging in alcohol/substance use if they answered yes to any of the above questions. Therefore, one dichotomous variable for parental substance use was available for analysis: alcohol/drug use? (yes/no).

Parental incarceration is measured using caregiver question C19 (have you ever been to jail?). It was dichotomous (yes/no) and was not transformed for the purposes of analysis.

Poverty is measured using caregiver questions C48A (currently receive food stamps?), C48B (currently receive AFDC?), and C48C (currently receive social security?). Variables were dichotomous (yes/no) and were not transformed for purposes of analysis. A new variable (cpoverty) was generated by coding each caregiver as living in poverty if they answered yes to any of the above questions. Therefore, one dichotomous variable for poverty (cpoverty) was available for analysis: Do you receive public assistance? (yes/no).

The third, and final, method of dealing with the independent variables calls for the creation of a risk index which creates an overall risk score by rating children individually by the number of risks present in their lives. For example, children living in poverty with no parent in jail, with mental illness, or with a substance use issue would be scored as 1 ; children with two of the identified risk factors would receive scores of 2; and so on. This method allows the researcher to easily evaluate the impact of the accumulation of risk and it is favorable when the independent variables are likely to be highly correlated (Burchinal et al. 2000).

A drawback of both the 2nd and 3rd methods is that they assume that all of the risks are equal and, therefore, impact a child in a similar way. The literature, however, does not support this assumption. For example, a child who has a parent who uses substances, but the family does not live in poverty, because the parents are able to work, and the parents do not suffer from mental illness or have not spent time in jail would be scored as a 1 . Other children would also receive scores of 1 if their parents were severely mentally ill with no other risk factors. It is apparent that the actual level of risk to these two children is likely to be different. Because individual children and families are complex, it is problematic to assume that risk manifests itself similarly in all families. Despite that, the use of risk factors and risk index scores to evaluate risk is well documented in the literature as a way of evaluating multiple risk models (Anda et al. 2002; Avalos-Jordan 2008; Burchinal et al. 2000; Chapman et al. 2007; Johnson and Waldfogel 2004; Johnson 2009; Mather and Adams 2006; Pirkola et al. 2005; Aaron and Dallaire 2010). Both risk factor analysis and risk index analysis were examined to determine the similarities and the differences in the approaches. Additionally, a significant contribution of this study is that the use of a multivariate probit regression model will allow the effects of each risk factor to be separated out from other risks so that differences in outcomes in the presence of different risks can be assessed. This allows the researcher to determine if different risks impact children in different ways rather than forcing the assumption that all risks impact children in similar ways.

\subsubsection{Dependent Variables (Outcomes)}

All dependent variables available for analysis were categorical, with the majority of them being dichotomous. In order to utilize multivariate probit regression techniques it was necessary to transform categorical variables that were not already dichotomous into dichotomous variables so that all variables entered into the regression equation were measured in the same way. Additionally, many of the dependent variables asked separate questions to address a variety of problem behaviors and child outcomes (for example, have you used pot and have you used cocaine rather than a general question about drug use). Again, for the purposes of analysis, these variables were combined into larger categories such as drug/alcohol use and crime. Entering a large number of variables into the regression equation would make the test less robust. A detailed account of how variables were transformed 
and/or combined follows. The dependent variables capture aspects of children's behaviors and emotional wellbeing. Just as the independent variable data results from caregivers' self-report, each of the dependent variables relied on youths' self-report.

School failure was measured by youth question Q41. Youth indicated whether they expected to be promoted to the next grade. The original response was coded as probably would, maybe would, probably would not, and definitely would not. The variable was dichotomized for the purpose of analysis by coding probably would and maybe would as yes and probably would not and definitely would not as no.

Being arrested was measured by youth question Q35E (have you ever been arrested?) and criminal behaviors were measured using a combination of variables: Q31B (are you a member of gangs?), QB10 (have you taken something worth over \$50?), QB12 (taken a car?), QB14 (set fire to someone else's property?), QB15 (damaged someone else's property?), QB18 (made someone give you money?), QB19 (attacked someone?), QB20 (forced someone to do sexual acts?), QB21 (carried a weapon?), QC10 (ever helped with drug sales?), and QC11 (ever sold drugs directly?). Q35E (have you ever been arrested?) is a dichotomous variable (yes/no) and was not transformed for purposes of the analysis. A new variable (ycrime) was generated by uniformly coding the already dichotomized variables (yes/no), and then coding each child as engaging in criminal behavior if they answered yes to any of the above questions. Therefore, two dichotomous variables for criminal behavior were available for analysis: Have you ever been arrested? (yes/no) and Have you engaged in criminal behaviors? (yes/no).

Behavioral difficulties was measured by youth question (serious fight in school?) and emotional difficulties was measured using a combination of variables: Q21F (feeling sad a problem?), QA1B (life seems meaningless), QA1D (I do not have much to be proud of), QA1E (I am a person of worth), QA1L (can't do anything right), and QA1M (my life is not very useful). All variables were dichotomized to create binary (yes/no) variables. A new variable (yemotion) was generated by using the newly created dichotomous variables and then coding each child as having emotional difficulties if they answered yes to any of the above questions.

Alcohol use was measured by youth question QC1 (ever used alcohol?) and substance use was measuring using a combination of variables: QC2 (ever sniffed glue?), QC3 (ever used marijuana?), QC4 (ever used psychedelics?), QC5 (ever used crack cocaine?), QC6 (ever used other forms of cocaine?), QC7 (ever taken a pill for a non-medical reason?), QC8 (ever used heroin?), and QC9 (ever used drugs with a needle?). Variables were dichotomous (yes/no) and were recoded only to ensure that all variables were coded in the same way. Variables for this outcome were not transformed for the purpose of analysis. A new variable (ydrug) was generated by coding each child as engaging in substance use if they answered yes to any of the above questions. Therefore, two dichotomous variables for alcohol/substance use were available for analysis: Have you ever used alcohol? (yes/no) and Have you ever used drugs? (yes/no).

\section{Results}

All analyses were completed using STATA 11. First, demographics and other descriptive statistics are presented to allow for a broader understanding of the sample. Second, a multivariate probit regression model is examined to more directly address the two primary research questions. The current study examines the differences between variables to determine the impact of parental risk factors on child outcomes.

\subsection{Demographics}

The Children at Risk (CAR) program consisted of 876 youth ranging in age from 10 to 13 years old. The majority of participants were 13 (44.5\%) or 12 (43.7\%). African-Americans made up 57.7\% of the sample. Other ethnic groups represented included Hispanic (34\%), white (5.7\%), and Asian $(1.7 \%)$. The sample was split fairly evenly on gender with $51.1 \%$ being male and $48.4 \%$ being female. Mothers represented the majority of caregivers at $79.9 \%$, while fathers $(7.6 \%)$ and grandmothers $(6.4 \%)$ represented the next largest groups. 
Table 2 describes the sample in relationship to the major variables being examined in the study (risk factors include parental mental illness, parental substance use, parental incarceration, and poverty; outcomes include school failure, criminal behavior, getting arrested, behavioral difficulties, emotional difficulties, alcohol use and drug use). The most prevalent parental characteristic was poverty with over $71 \%$ reporting that they were currently experiencing poverty, as defined by their receiving public assistance. Parental incarceration was present in just over $17 \%$ of the sample and parental mental illness, and parental substance use was similar at $13 \%$ and $11 \%$, respectively. When examining the dependent variables (school failure, criminal behavior, getting arrested, behavioral difficulties, emotional difficulties, alcohol use and drug use) the most prevalent characteristic was emotional difficulty (66\%), following by drug use (45\%), behavioral difficulties (42\%) and criminal behaviors (41\%).

Table 2. Descriptive Statistics.

\begin{tabular}{lc}
\hline \multicolumn{1}{c}{ Descriptive Statistics for Primary Variables of Interest } \\
\hline \multicolumn{1}{c}{ Variables } & Percentage \\
\hline Independent Variables \\
\hline Parental Mental Illness \\
Parental Substance Use & $13.72 \%$ \\
Parental Incarceration & $11.58 \%$ \\
Poverty & $17.66 \%$ \\
\hline Dependent Variables & $71.60 \%$ \\
\hline School Failure & \\
Criminal Behavior & $7.16 \%$ \\
Arrested & $41.17 \%$ \\
Behavioral Difficulty & $8.11 \%$ \\
Emotional Difficulty & $42.60 \%$ \\
Alcohol Use & $66.59 \%$ \\
Drug Use & $29.83 \%$ \\
\hline
\end{tabular}

When analyzing the validity of the model proposed in this study, it is important to determine that the independent variables are not highly correlated so that each construct can be assumed to be measuring different phenomenon within the sample. Similarly, the presence of high correlation coefficients among the dependent variables dictates that a multivariate analysis is necessary rather than separate univariate analyses (Long 1997). Table 3 illustrates that there is not significant correlation among the independent variables and Table 1 (presented previously) illustrates enough correlation between the dependent variables to justify the use of multivariate analysis techniques.

Table 3. Correlations among Independent Variables (Risk Factors).

\begin{tabular}{ccccc}
\hline \multicolumn{4}{c}{ Correlation Table-Independent Variables (Risk Factors) } \\
\hline & Parental Mental Illness & Parental Substance Use & Parental Incarceration & Poverty \\
\hline Parental Mental Illness & 1.0000 & & & \\
Parental Substance Use & $0.1742^{* * *}$ & 1.0000 & 1.0000 & \\
Parental Incarceration & 0.0009 & $0.1416^{* * *}$ & $0.0526^{+}$ & 1.0000 \\
Poverty & -0.0108 & -0.0009 &
\end{tabular}

\subsection{Regression Results}

The results of the probit regression are reported in Table 4. For example, in the first column, the school performance index appears to be related only to parental mental illness as indicated by a significant $(p<0.05)$ finding on that risk only. The standard error for the coefficients (reported in parenthesis) provides an idea of the variability of the estimated coefficients. For example, a smaller 
standard error (closer to zero) relative to the coefficient indicates possible significance. For each equation, the constant is the value of the index when all of the risks are equal to zero.

Table 4. Probit Regression Results.

\begin{tabular}{cccccccc}
\hline & \multicolumn{7}{c}{ Dependent Variables } \\
\hline & School Failure & Crime & Arrested & Behavioral & Emotional & Alcohol & Drugs \\
\hline IV & & & & & \\
\hline Parental Mental & $0.3552^{* *}$ & $0.2124^{+}$ & $0.5849^{* * *}$ & $0.3237^{* *}$ & 0.0415 & 0.1654 & 0.0569 \\
Illness & $(0.1730)$ & $(0.1291)$ & $(0.1571)$ & $(0.1269)$ & $(0.1322)$ & $(0.1304)$ & $(0.1250)$ \\
\hline Parental & 0.0132 & $0.4345^{* * *}$ & $0.2532^{+}$ & -0.0201 & -0.1430 & 0.1396 & 0.1440 \\
Substance Use & $(0.2093)$ & $(0.1426)$ & $(0.1764)$ & $(0.1401)$ & $(0.1412)$ & $(0.1422)$ & $(0.1338)$ \\
\hline Parental & -0.1381 & $0.3806^{* * *}$ & $0.4417^{* * *}$ & $0.1943 *$ & 0.0351 & $0.2087^{*}$ & $0.3076^{* * *}$ \\
Incarceration & $(0.1847)$ & $(0.1172)$ & $(0.1513)$ & $(0.1147)$ & $(0.1185)$ & $(0.1190)$ & $(0.1103)$ \\
\hline Poverty & 0.2381 & -0.1054 & -0.0010 & -0.0578 & $0.1635^{*}$ & $-0.2563^{* * *}$ & $-0.1973^{* *}$ \\
& $(0.1570)$ & $(0.0974)$ & $(0.1432)$ & $(0.0963)$ & $(0.0978)$ & $(0.0982)$ & $(0.0912)$ \\
\hline Constant & $-1.6825^{* * *}$ & $-0.2917^{* * *}$ & $-1.6483^{* * *}$ & $-0.2243^{* *}$ & $0.3177^{* * *}$ & $-0.4197^{* * *}$ & -0.0086 \\
& $(0.1439)$ & $(0.0867)$ & $(0.1333)$ & $(0.0857)$ & $(0.0865)$ & $-0.0861)$ & $(0.0820)$ \\
\hline
\end{tabular}

All of the parental risk factors identified in the study were found to have a significant impact on at least one child outcome. Interestingly, emotional difficulties were not significantly impacted by any of the identified parental characteristics. This may be explained by the high prevalence of emotional difficulties in the sample $(66 \%)$. Additionally, none of the outcome variables were shown to be significantly impacted by more than two risk factors.

For clarity, consider the coefficient for school failure on the first independent variable, parental mental illness. The coefficient is positive indicating that as parental mental illness increases so does school failure. This finding is significant $(p<0.05)$ indicating that the independent variable parental mental illness was found to have a significant impact on child school failure. The coefficients themselves are an indication of the amount of effect the independent variable will have on the probit index discussed earlier. The probit index is then used to predict the probability of an outcome occurring, an easier and more straightforward finding to interpret. Those predicted probabilities will be reported later in Table 5.

All independent variables were found to have a significant impact (at least $p<0.05$ ) on one or more dependent variables. Parental mental illness and parental incarceration were both found to have a significant impact on three different dependent variables. Both parental mental illness and parental incarceration showed a significant impact $(p<0.01)$ on whether a youth gets arrested. Additionally, parental incarceration was found to impact youth participation in crime and drug use $(p<0.01)$. Parental mental illness impacted school failure and behavioral difficulties $(p<0.05)$. Parental substance use was found to significantly impact youth crime $(p<0.01)$, and poverty was found to impact both drug use $(p<0.05)$ and alcohol use $(p<0.01)$.

When examining the effects of each independent variable on outcome probabilities, it is possible to see the percentage of change in the risk of experiencing negative outcomes when there are one or multiple risks present. All of the dependent variables, excluding emotional difficulties, showed an increase in negative outcomes as risk increased. The risk of school failure increased by $7 \%$ when comparing no risk factors present in the child's life to all four risk factors being present. The same comparison showed criminal behaviors increasing by $36 \%$, getting arrested increased by $33 \%$, behavioral difficulties by $19 \%$, alcohol use by $11 \%$, and drug use by $11 \%$. Additionally, the large majority of outcomes increased when the number of risk factors increased incrementally from one factor to three factors to four factors. This suggests that as the presence of risk increases negative child outcomes increase, however, it does not make it possible for the researcher to determine whether one risk factor has a greater impact on a particular outcome over another. A simple assumption that 
increased risk leads to increased negative outcomes may underestimate the impact of specific risk factors on specific outcomes. If this assumption were true, it would be expected that each probability of each outcome would increase in approximately the same way on all comparisons. The current analysis does not support this.

\subsection{Effects and Predicted Outcome Probabilities}

Coefficients from the probit model can be difficult to interpret because they measure the change in the unobservable indices associated with a one unit change in the corresponding risk factors (irving.vassar.edu/faculty/wl/Econ210/LPMf02.pdf). For this reason, it is helpful also to examine the effects of each risk factor on the outcome probabilities for each dependent variable to more easily interpret the probit results.

An examination of the effects of changes in the independent variable (risk) on the probabilities of the outcomes allows the researcher to quantify the relationship between the risk factors and the outcome probabilities. Effects is defined as the change in predicted probability associated with changes in the independent variable (risk factors) (Anderson and Newell 2003). In other words, the sign and magnitude of the effect indicate the impact of the explanatory variable (risk factor) on the probability that the outcome will occur. Table 5 will show the predicted probability for each dependent variable being examined in the study. Each table illustrates the probability that an outcome will occur when there is only one risk factor, no risks factors, three risk factors, and when all four risk factors are present.

Table 5. Predicted Probabilities for Child Outcomes.

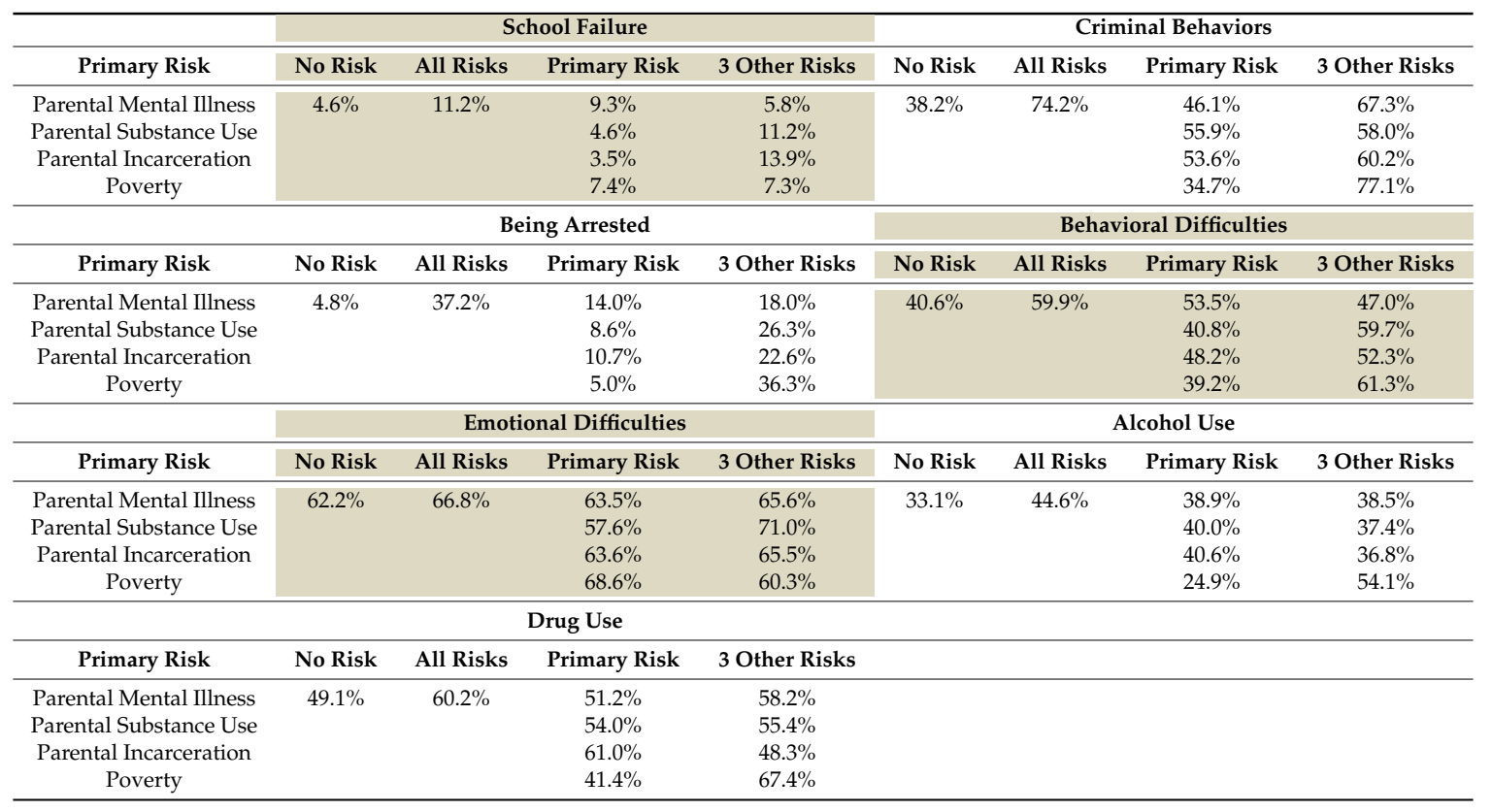

When examining the above table, several interesting findings should be noted. These findings support the assertion that risk manifests itself differently and that separate risk factors cannot be viewed as equal. The accumulation of risk indeed led to an increased occurrence of the outcomes being examined, but, more importantly, the results clearly show that separate risks impact different outcomes differently. For example, the probability of being arrested increased from $4.8 \%$ when there were no risks to $37.2 \%$ when all four risk factors were present, indicating a $32.4 \%$ increase in the probability of being arrested as risks accumulate. All risk factors, except for poverty, were shown to increase the probability of criminal behaviors between $7.9 \%$ (parental mental illness) and $17.7 \%$ (parental substance use). 
Notice that the probability of school failure increases from $4.6 \%$ when there were no risks to $11.2 \%$ when all four risk factors were present, indicating a $6.6 \%$ increase in school failure as risks accumulate. Parental mental illness alone increased the probability of this outcome to 9.3\% (a difference of $4.7 \%$ ), but parental substance use contributed to no increased probability of school failure. Parental incarceration and poverty were shown to increase the probability of school failure minimally $(1.1 \%$ and $2.8 \%$ respectively). Even when all risks are present, the overall probability of school failure is relatively low (11.2\%) among the children in this sample.

Most notably in this table is the high probability that children in this sample will experience emotional difficulties regardless of risk (approximately 65\%). The probability differs by less than $5 \%$ when there are no risk factors or when there are all four risk factors present. Additionally, none of the individual risk factors were shown to significantly impact the probability of this outcome.

\subsection{Risk Index Analysis}

Previous studies have examined risk by simply creating a risk index score that represents the cumulative number of risks faced by each child (Aaron and Dallaire 2010; Anda et al. 2002; Avalos-Jordan 2008; Burchinal et al. 2000; Chapman et al. 2007; Johnson and Waldfogel 2004; Johnson 2009; Mather and Adams 2006; Pirkola et al. 2005). A drawback of this method is that they assume that all of the risks are equal and, therefore, impact a child in a similar way. The literature, however, does not support this assumption.

To test Hypothesis 1, a risk index was created from existing data, and each child was assigned a score between 0 and 4 . The index was a simple addition of the number of risk factors that were present in each child's life. A multivariate probit regression model was run using the risk index score as the independent variable. The results of that analysis indicate that an accumulation of risk does significantly impact several of the child outcomes being examined. Criminal behaviors and being arrested were most significantly impacted by an increasing number of risk factors, and behavioral difficulties approached significance. Interestingly, alcohol use and drug use were not found to be significantly impacted by an increasing number of risk factors. This finding suggests that a simple accumulation of risk may not affect all outcomes in the same way.

The first probit model examined the impact of individual risks when other risks known to impact child outcomes were controlled for by the model (Table 4). In order to determine the impact of accumulated risk, a second probit regression was conducted using a risk index score. This index score simply counts the number of risk factors that are present in a child's life and assigns a value of 0-4. If a child has no risks s/he will be scored as a zero. If $\mathrm{s} /$ he has all four risks, the score will be four and so on. Table 6 presents the descriptive statistics for the risk index variable, including frequencies and mean score.

Table 6. Descriptive Statistics of Risk Index Score.

\begin{tabular}{cccc}
\hline Risk Index Score & Frequency & Percentage of Sample & Mean Score \\
\hline 0 & 161 & $19.01 \%$ & \\
1 & 458 & $54.07 \%$ & \\
2 & 177 & $20.90 \%$ & \\
3 & 44 & $5.19 \%$ & \\
4 & 7 & $0.83 \%$ & \\
\hline
\end{tabular}

Notice from the probit regression findings reported in Table 7 show that a simple accumulation of risk was not found to significantly impact all negative outcomes. The outcomes most impacted by the presence of multiple risk factors were criminal behaviors, being arrested, and behavioral difficulties. School failure approached significance, and that reduced impact may be accounted for by special education programming and other interventions used in the school to address problem behaviors. 
Table 7. Probit Regression using Risk Index Score.

\begin{tabular}{|c|c|c|c|c|c|c|c|}
\hline & \multicolumn{7}{|c|}{ Dependent Variables } \\
\hline & School Failure & Crime & Arrested & Behavioral & Emotional & Alcohol & Drugs \\
\hline \multicolumn{8}{|l|}{ IV } \\
\hline Constant & $\begin{array}{c}-1.6068^{* * *} \\
(0.1160)\end{array}$ & $\begin{array}{c}-0.4465^{* * *} \\
(0.0768)\end{array}$ & $\begin{array}{c}-1.7947^{* * *} \\
(0.1197)\end{array}$ & $\begin{array}{c}-0.2978^{* * *} \\
(0.0755)\end{array}$ & $\begin{array}{c}-1.7317^{* * *} \\
(0.1324)\end{array}$ & $\begin{array}{c}-0.5612 * * * \\
(0.0786)\end{array}$ & $\begin{array}{c}-0.1354 \text { * } \\
(0.0732)\end{array}$ \\
\hline
\end{tabular}

\section{Discussion}

\subsection{Primary Risk Factors Examined}

Parental incarceration and parental mental illness were shown to be linked to the most outcomes. Parental mental illness was the only risk factor shown to have a significant impact on school failure when the effects of other risk factors were controlled for. Additionally, behavioral difficulties showed a link to only parental mental illness. This finding suggests that other risk factors believed to play a role in those negative outcomes may not contribute a significant amount of risk when parental mental illness is present, and the seriousness of parental mental illness may trump the negative effects of other risks factors.

Another risk factor shown to have a significant impact on multiple outcomes was parental incarceration. Parental incarceration significantly impacted the largest number of outcomes, with significance $(p<0.05)$ on three outcomes (criminal behaviors, being arrested, drug use) and the risk factor approached significance $(p<0.10)$ on two other outcomes (behavioral difficulties and alcohol use). Again, this finding suggests that the risk posed by parental incarceration may overrule the negative effects of other risk factors.

Interestingly, the two most significant risk factors (parental mental illness and parental incarceration) were found to impact different child outcomes. The only overlap in the outcomes significantly impacted was the effect on whether a child had been arrested. All other outcomes were impacted differently by the two risk factors. Parental mental illness significantly impacted school failure and behavioral difficulties, whereas parental incarceration significantly impacted criminal behaviors and drug use. This finding further supports the argument that it is not simply a presence of risk, any risk, which leads to negative outcomes but rather that specific risk factors put children at risk of displaying specific negative outcomes.

Parental incarceration and parental substance use were shown to have the most significant impact on criminal behaviors when examining the impact of each risk factor separately. Both factors increased the likelihood of engaging in criminal acts by approximately $15 \%$ when other risk factors were controlled for. Parental incarceration and parental mental illness were shown to have the most significant impact on being arrested when examining the impact of each risk factor separately. Both factors increased the likelihood of getting arrested by approximately 10\%. Parental incarceration and poverty were shown to have the most significant impact on drug use when examining the impact of each risk factor separately. Parental incarceration increased the likelihood of drug use by $11 \%$. Interestingly, poverty was shown to decrease the likelihood of both drug use and alcohol use by approximately $10 \%$ suggesting that it may be a protective factor against drug use. This finding is contradictory to research finding in the literature on the impact of poverty on children (Corcoran and Chaudry 1997; Duncan et al. 1994; Duncan and Rodgers 1988; McLeod and Shanahan 1993).

It is also interesting to take note of the risk factors that were not found to significantly impact child outcomes. Thousands of dollars have been spent over the years to examine the effects of poverty 
on children and families. The findings of this study, however, do not show poverty as significantly impacting child outcomes when the other risks are controlled for. This could be because of the high percentage of poverty in the sample, nonetheless, it is interesting to consider if it is not poverty, but other risks that often occur with poverty, which lead to negative outcomes. In which case, it can be argued that resources used to examine the impact of poverty would be better used to research other risks that often occur in families not touched by poverty (such as parental mental illness and parental substance use).

The notion that specific risk factors contribute to specific outcomes is somewhat contradictory of previous research that asserts that it is simply the accumulation of risk, and not specific risk factors, that contribute to negative child outcomes. These findings challenge a fundamental assumption of previous multiple risk models-a simple accumulation of risk, regardless of the type of risk, lead to increased negative outcomes. The current findings attempt to recognize that not all risks are created equal, and children who experience different types of risk respond differently and have different types of outcomes.

\subsection{Implications for Policy}

The results of this study have specific implications for today's social policies. The impact of parental incarceration is largely ignored by policy makers and the various branches of the criminal justice system, law enforcement, judicial, and corrections. Previous research on parental incarceration supports the findings of this study that parental incarceration has a significant impact on child outcomes. Parental incarceration in this study was shown to be more significantly linked to negative outcomes than any other parental risk factor. Policies today should reflect an increased awareness of the impact of parental incarceration on children. Imprisoning parents may lead to greater criminal behavior and alcohol/drug abuse in the next generation. This potential generational impact indicates a need to consider parenthood as an extenuating circumstance when sentences are determined and indicate a need for an increased use of community-based corrections when children will be impacted by the incarceration of a parent. When community corrections cannot be used it is important that children and their caregivers are given increased social support when a parent goes to prison. This support may include increased economic support (food stamps, Medicaid, TANF, etc.), intensive case management services to address ongoing needs, mental health services to cope with trauma, grief, and loss, and programs to assist families in staying better connected to one another during a parent's imprisonment.

Comprehensive policies need to be developed that address multiple risks and can better assess for the presence of various risks in a child's life. The findings of this study suggest that different risk factors are connected to different negative outcomes, but all negative outcomes have been shown in previous literature to contribute to difficulties throughout a person's lifespan. By examining the interconnection of various risk factors, it will be easier to develop policies that break the cycle of poverty, drug use, criminal behavior, and untreated mental illness. The findings of this study support the need for policies and programs that address known risks, however, contrary to many policies today which focus on children identified as high risk, these findings support the argument that many times the presence of only one risk can lead to negative outcomes and therefore needs to be addressed by policies and programming. In fact, depending on the outcome being addressed, some risks are more critical to address. A school social worker trying to reduce the number of retentions in her school may be better served to create programming that addresses the impact of parental mental illness on poverty. No risk factor is insignificant, and children do not have to have multiple risks for them to display negative outcomes. They just have to have the right kind of risk. The presence of only one risk factor or the presence of multiple risk factors will all significantly impact the likelihood of negative outcomes. Therefore, policy makers must take into account the specific outcomes being addressed. Policies need to be expanded to include children and neighborhoods that may not be considered high risk but may also face a significant likelihood of negative outcomes when certain risks are present. 


\subsection{Limitations of the Study}

There are some methodological limitations in the present study. First, secondary analysis was performed on data that were collected to serve the interest and perspective of the original researchers. The data were collected to test the effectiveness of an intervention over a period of years and was never intended to test the hypotheses of this research study. This resulted in a lack of control over the independent and dependent variables, and some constructs were forced to be measured in a way they would not have been measured if collecting original data. Additionally, some variables of interest were not available in the dataset and were therefore left out of the analysis. Secondly, the absence of ratio level data in the dataset required some variables to be reduced to nominal level to include other nominal variables in the analysis that measured important constructs. This practice resulted in the loss of some detail on certain variables. Thirdly, the construct of parental incarceration was measured by whether a child had a parent or caregiver go to jail in the past year. This fails to capture the lifetime prevalence of parental incarceration. Fourthly, all of the children in the current study were identified as high risk by the original researchers and therefore there are not children in the sample who are low risk or who have no risks for negative outcomes. This makes it impossible to generalize the findings to other children outside of the sample population. Lastly, several possible child characteristics that have been shown to protect children against negative outcomes were not captured in the dataset and therefore could not be controlled for in the analysis. Future research should include those protective factors that have been shown to decrease the risk of negative child outcomes.

This study was reviewed by the Institutional Review Board of University of Louisville, Louisville, KY on 14 June 2010, tracking number 10.0304. The study was determined to be exempt due to the use of publicly available secondary data.

\section{Conclusions}

The results of this study demonstrate that: (a) as risk factors increase the probability of negative child outcomes also increase; (b) all of the parental characteristics identified as risk factors were shown to have a significant impact on one or more child outcomes; (c) specific parental risk factors seem to contribute to specific child outcomes; (d) children with a parent incarcerated are more likely than those with other parental risk factors to display negative outcomes; and (e) participation in crime, being arrested, and drug use were found to be most impacted, showing significance on at least two risk factors.

The findings of the current study highlight the need for policy makers and practitioners alike to search out a more nuanced understanding of risk and how it manifests itself in children and families. Understanding the unique effect of parental incarceration is a fine and noble goal, but we must also consider other environmental and ecological factors that impact child development. Multisystem therapies, family centered therapies, and community approaches are some examples of interventions found to be helpful in addressing the complex lives and circumstances of these families (Graham and Harris 2013). Additionally, the challenges faced by researchers in this field are great. A lack of longitudinal data or relevant data in general makes it difficult to fully examine this vulnerable population. Standardized reporting systems across state and federal prison systems would aid in this process.

Conflicts of Interest: The author declares no conflict of interest.

\section{References}

Aaron, Lauren, and Danielle Dallaire. 2010. Parental incarceration and multiple risk experiences: Effects on family dynamics and children's delinquency. Journal of Youth and Adolescence 39: 1471-84. [CrossRef] [PubMed]

Ackerson, Barry J. 2003. Parents with serious and persistent mental illness: Issues in assessment and services. Social Work 48: 187-94. [CrossRef] [PubMed] 
Anda, Robert F., Charles L. Whitfield, Vincent J. Felitti, Daniel P. Chapman, Valerie J. Edwards, and Shanta R. Dube. 2002. Adverse childhood experiences, alcoholic parents, and later risk of alcoholism and depression. Psychiatric Services 53: 1001-9. [CrossRef] [PubMed]

Anderson, Soren, and Richard G. Newell. 2003. Simplified marginal effects in discrete choice models. Economics Letters 81: 321-26. [CrossRef]

Arditti, Joyce A., Jennifer Lambert-Shute, and Karen Joest. 2003. Saturday morning at the jail: Implications of incarceration for families and children. Family Relations 52: 195. [CrossRef]

Avalos-Jordan, N. 2008. A Study of Parental Practices, Poverty, and Social Connection to Neighbors and Their Impact on Children's Emotional Well-Being and Behavior. Unpublished Masters thesis, California State University, Long Beach, CA, USA.

Bloom, Barbara, and David Steinhart. 1993. Why Punish the Children? A Reappraisal of the Children of Incarcerated Mothers in America. San Francisco: National Council on Crime and Delinquency.

Brooks-Gunn, Jeanne, and Greg J. Duncan. 1997. The effects of poverty on children. Children and Poverty 7: 55-71. [CrossRef]

Burchinal, Margaret, Joanne E. Roberts, Steven Hooper, and Susan A. Zeisel. 2000. Cumulative risk and early cognitive development: A comparison of statistical risk models. Developmental Psychology 36: 793-807. [CrossRef] [PubMed]

Chapman, Daniel P., Shanta R. Dube, and Robert. F. Anda. 2007. Adverse childhood events as risk factors for negative mental health outcomes. Psychiatric Annals 37: 359-64.

Chassin, Laurie, Patrick Curran, Andrea Hussong, and Craig R. Colder. 1996. The relation of parent alcoholism to adolescent substance use: A longitudinal follow-up study. Journal of Abnormal Psychology 105: 70-80. [CrossRef] [PubMed]

Chib, Siddhartha, and Edward Greenberg. 1998. Analysis of multivariate probit models. Biometrika 85: 347-61. [CrossRef]

Cho, Rosa M. 2010. Maternal incarceration and children's adolescent outcomes: Timing and dosage. Social Service Review 84: 257-82. [CrossRef]

Colder, Craig R, Laurie Chassin, Eric M. Stice, and Patrick J. Curran. 1997. Alcohol expectancies as potential mediators of parent alcoholism effects on the development of adolescent heavy drinking. Journal of Research on Adolescence 7: 349-74. [CrossRef]

Cooper, Robert, and Will J. Jordan. 2003. Cultural issues in comprehensive school reform. Urban Education 38: 380-97. [CrossRef]

Corcoran, Mary E., and Ajay Chaudry. 1997. The dynamics of childhood poverty. Children and Poverty 7: 40-54. [CrossRef]

Dallaire, Danielle H. 2007. Incarcerated mothers and fathers: A comparison of risks for children and families. Family Relations 56: 440-53. [CrossRef]

Davenport, Yolande B., Carolyn Zahn-Waxler, Marvin L. Adland, and Anne Mayfield. 1984. Early child rearing practices in families with a manic depressive parent. American Journal of Psychiatry 141: 230-35. [PubMed]

Downey, Geraldine, and James C. Coyne. 1990. Children of depressed parents: An integrative review. Psychological Bulletin 108: 50-76. [CrossRef] [PubMed]

Downey, Lois, R. A. Engelberg, Randall J. Curtis, William E. Lafferty, and D. L. Patrick. 2009. Shared priorities of end-of-life period. Journal of Pain Symptom Management 37: 175-88. [CrossRef] [PubMed]

Duncan, Greg J., and Willard Rodgers. 1988. Longitudinal aspects of childhood poverty. Journal of Marriage and Famil 50: 1007-21. [CrossRef]

Duncan, Greg J., Jeanne Brooks-Gunn, and Pamela K. Klebanov. 1994. Economic deprivation and early-childhood development. Child Development 65: 296-318. [CrossRef] [PubMed]

Finkelstein, Norma, Elke Rechberger, Lisa A. Russell, Nancy R. Van DeMark, Chanson D. Noether, and Maura O'Keefe. 2005. Building resilience in children of mothers who have co-occurring disorders and histories of violence: Intervention model and implementation issues. Journal of Behavioral Health Science $\mathcal{E}$ Research 32: 141-54.

Furstenberg, Frank F., Thomas D. Cook Jr., Jacquelynn Eccles, Glen. H. Elder Jr., and A. J. Sameroff. 1999. Managing to Make It: Urban Families and Adolescent Success. Chicago: University of Chicago Press.

Gibbons, Robert D., and Virginia Wilcox-Gok. 1998. Health service utilization and insurance coverage: A multivariate probit analysis. Journal of American Statistical Association 93: 63-72. [CrossRef] 
Goelman, Hilel, Bozena Zdaniuk, W. Thomas Boyce, Jeffery M. Armstrong, and Marilyn J. Essex. 2014. Maternal mental health, child care quality, and children's behavior. Journal of Applied Developmental Psychology 35: 347-56. [CrossRef]

Golden, Renny. 2005. War on the Family: Mothers in Prison and the Families They Leave Behind. New York: Routledge.

Graham, James A., and Yvette R. Harris. 2013. Children of color and parental incarceration: Implications for research, theory, and practice. Journal of Mulitcultural Counseling and Development 41: 66-81. [CrossRef]

Grant, Bridget F. 2000. Estimates of US children exposed to alcohol abuse and dependence in the family. American Journal of Public Health 90: 112-15. [PubMed]

Greenberg, Rivka. 2006. Children and families: Mothers who are incarcerated. Women E Therapy 29: 165-79.

Greenberg, Mark T., Liliana J. Lengua, John D. Coie, and Ellen E. Pinderhughes. 1999. Predicting developmental outcomes at school entry using a multiple-risk model: Four American communities. Developmental Psychology 35: 403-17. [CrossRef] [PubMed]

Gutijahr, Angela. 2007. Child Resilience Program: An Intervention for Children of Chronically Mentally Ill Parents. Unpublished dissertation, Spalding University, Louisville, KY, USA.

Hagen, Kristine A., and Barbara J. Myers. 2003. The effect of secrecy and social support on behavioral problems in children of incarcerated women. Journal of Child and Family Studies 12: 229-42. [CrossRef]

Hairston, Creasie F. 1995. Fathers in prison. In Children of Incarcerated Parents. Edited by Denise Johnston and Katherine Gables. Lexington: Lexington Books.

Hairston, Creasie F. 2007. Focus on Children with Incarcerated Parents: An Overview of the Research Literature. Baltimore: Annie E. Casey Foundation.

Hairston, Creasie F., and William Oliver. 2006. Women's experiences with men's incarceration and reentry. Women, Girls \& Criminal Justice 7: 65-80.

Hairston, Creasie F., and William Oliver. 2007. Domestic Violence and Prisoner Reentry: Experiences of African American Men and Women. New York: Vera Institute of Justice.

Harpaz-Rotem, Ilan, Robert A. Rosenheck, and Rani Desai. 2006. The mental health of children exposed to maternal mental illness and homelessness. Community Mental Health Journal 42: 437-48. [CrossRef] [PubMed]

Harrell, A. V., Shannon Cavanagh, and Sanjeev Sridharan. 1998. Evaluation of the Children at Risk Program in Austin, Texas; Bridgeport, Connecticut; Memphis, Tennessee; Savannah, Georgia; and Seattle, Washington; 1993-1997. Washington: The Urban Institute.

Hill, Jonathan. 1996. Parental Psychiatric Disorder and the Attachment Relationship. Cambridge: University Press.

Hill, Nancy. E., and Lorraine C. Taylor. 2004. Parental school involvement and children's academic achievement. Current Directions in Psychological Science 31: 161-64. [CrossRef]

Hyppolite, M. L. 2017. Examining Four Major Vulnerabilities Faced by Families. Community Mental Health. Edited by Jessica and Samuel Rosenberg, in press.

Johnson, Rucker C. 2009. Ever-increasing levels of parental incarceration and the consequences for children. In Do Prisons Make Us Safer? Edited by S. Raphael and M. A. Stoll. New York: Russell Sage Foundation.

Johnson, Elizabeth I., and Beth Easterling. 2012. Understanding unique effects of parental incarceration on children: Challenges, progress, and recommendations. Journal of Marriage and Family 74: 342-56. [CrossRef]

Johnson, Elizabeth I., and Jane Waldfogel. 2004. Children of incarcerated parents: Multiple risks and children's living arrangements. In Imprisoning America: The Social Effects of Mass Incarceration. Edited by Mary Pattillo, David Weiman and Bruce Western. New York: Russell Sage Foundation.

Kinner, Stuart A., Rosa Alati, Jake M. Najman, and Gail M. Williams. 2007. Do paternal arrest and imprisonment lead to child behavior problems and substance use? A longitudinal analysis. Journal of Child Psychology and Psychiatry 48: 1148-56. [CrossRef] [PubMed]

Kjellstrand, Jean M., and J. Mark Eddy. 2011. Mediators of the effect of parental incarceration on adolescent externalizing behaviors. Journal of Community Psychology 39: 551-65. [CrossRef] [PubMed]

Lareau, Annette. 1996. Assessing parent involvement in school: A critical analysis. In Family-school links: How do they affect educational outcomes? Edited by Alan Booth and Judith F. Dunn. Mahwah: Lawrence Erlbaum, pp. 57-64.

La Vigne, Nancy G., Elizabeth Davies, and Diana Brazzell. 2008. Broken Bonds: Understanding and Addressing the Needs of Children with Incarcerated Parents. Washington: Urban Institute Justice Policy Center.

LaMont, Elizabeth D. 2014. Vulnerable children and families: Voices from the national landscape. Child and Adolescent Social Work Journal 3: 251-65. [CrossRef] 
Long, Scott J. 1997. Regression Models for Categorical and Limited Dependent Variables. London: SAGE Publications. Mackintosh, Virginia H., Barbara J. Myers, and Suzanne S. Kennon. 2006. Children of incarcerated mothers and their caregivers: Factors affecting the quality of their relationships. Journal of Child and Family Studies 15: 581-96. [CrossRef]

Mather, Mark, and Dia Adams. 2006. The Risk of Negative Child Outcomes in Low-income Families. Baltimore: The Annie E. Casey Foundation and Population Reference Bureau.

McLeod, Jane D., and Michael J. Shanahan. 1993. Poverty, parenting and children's mental health. American Sociological Review 58: 351-66. [CrossRef]

Miller, Keva M. 2006. The impact of parental incarceration on children: An emerging need for effective interventions. Child and Adolescent Social Work Journal 23: 472-86. [CrossRef]

Moe, Angela M., and Kathleen J. Ferraro. 2006. Criminalized mothers: The value and devaluation of parenthood from behind bars. Women $\mathcal{E}$ Therapy 29: 135-64.

Moses, Marilyn. 1995. Keeping Incarcerated Mothers and Their Daughters Together: Girl Scouts beyond Bars (No. 156217). Washington: National Institute of Justice.

Mowbray, Carol, Sondra Schwartz, Deborah Bybee, Jan Spang, Alba Rueba-Riedle, and Daphna Oyersman. 2000. Mothers with a mental illness: Stressors and resources for parenting and living. Families in Society: The Journal of Contemporary Human Services 81: 118-29. [CrossRef]

Murray, Joseph, David P. Farrington, and Ivanna Sekol. 2012. Children's Antisocial behavior, mental health, drug use, and educational performance after parental incarceration: A systemic review and meta-analysis. Psychological Bulletin 138: 175-210. [CrossRef] [PubMed]

Muthen, Bengt. 1989. Dichotomous factor analysis of symptom data. Sociological Methods Research 18: 19-65. [CrossRef]

Nichols, Emily B., Ann B. Loper, and J. Patrick Meyer. 2016. Promoting educational resiliency in youth with incarcerated parents: The impact of parental incarceration, school characteristics, and connectedness on school outcomes. Journal of Youth and Adolescence 45: 1090-109. [CrossRef] [PubMed]

Nurse, Anne M. 2002. Fatherhood Arrested: Parenting From Within the Juvenile Justice System. Nashville: Vanderbilt University Press.

Oates, Margaret. 1997. Patients as parents: The risk of children. British Journal of Psychiatry 170: 22-27.

Osborne, Cynthia, and Lawrence M. Berger. 2009. Parental substance abuse and child well-being. Journal of Family Issues 30: 341-70. [CrossRef]

Oyersman, Daphna, Carol Mowbray, Paula Meares, and Kirsten Firminger. 2000. Parenting among mothers with a serious mental illness. American Journal of Orthopsychiatry 70: 296-315.

Oyersman, Daphna, Deborah Bybee, and Carol Mowbray. 2002. Influences of maternal mental illness on psychological outcomes for adolescent children. Journal of Adolescence 25: 587-602.

Pirkola, Sami, Erkki Isometsa, Hillevi Aro, Laura Kestila, Juha Hamalaninen, and Juha Veijola. 2005. Childhood adversities as risk factors for adult mental disorders. Social Psychiatry E Psychiatric Epidemiology 40: 769-77.

Poehlmann, Julie. 2005. Children's family environments and intellectual outcomes during maternal incarceration. Journal of Marriage and Family 67: 1275. [CrossRef]

Poehlmann, Julie, Rebecca J. Shlafer, Elizabeth Maes, and Ashley Hanneman. 2008. Factors associated with young children's opportunities for maintaining family relationships during maternal incarceration. Family Relations 57: 267-80. [CrossRef]

Robins, Lee N. 1978. Sturdy childhood predictors of adult antisocial behavior: Replications from longitudinal studies. Psychological Medicine 8: 611-22. [CrossRef] [PubMed]

Roll, Susan, and Jean East. 2014. Financially vulnerable families and the child care cliff effect. Journal of Poverty 18: 169-87. [CrossRef]

Roy, Kevin M., and Omari L. Dyson. 2005. Gatekeeping in context: Baby mama drama and the involvement of incarcerated fathers. Fathering 3: 289-310. [CrossRef]

Sameroff, Arnold J., W. Todd Bartko, Alfred Baldwin, Clare Baldwin, and Ronald Seifer. 1998. Family and social influences on the development of child competence. In Families, Risk, and Competence. Edited by M. Lewis and C. Feiring. Mahwah: Lawrence Erlbaum.

Smith, Aaron, Kerry Krisman, Anne L. Strozier, and Marsha A. Marley. 2004. Breaking through the bars: Exploring the experiences of addicted incarcerated parents whose children are cared for by relatives. Families in Society 85: 187-95. [CrossRef] 
Travis, Jeremy, and Michelle Waul. 2003. Prisoners once removed: The children and families of prisoners. In Prisoners Once Removed: The Impact of Incarceration and Reentry on Children, Families and Communities. Edited by Jeremy Travis and Michelle Waul. Washington: The Urban Institute Press, pp. 1-29.

Travis, Jeremy, Elizabeth C. McBride, and Amy L. Solomon. 2003. Families Left Behind: The Hidden Costs of Incarceration and Reentry. Washington: The Urban Institute.

Trembley, Richard, Frank Vitaro, Daniel Nagin, Linda Pagani, and Jean R. Seguin. 2003. The Montreal longitudinal and experimental study: Rediscovering the power of descriptions. In Taking Stock of Delinquency: An Overview of Findings from Contemporary Longitudinal Studies. Edited by Terence P. Thornberry and Marvin D. Krohn. New York: Kluwer Academic, pp. 205-54.

U.S. Department of Justice. 2010. Parents in Prison and Their Minor Children; Washington: Bureau of Justice Statistics.

Wakefield, Sara. 2007. The Consequences of Incarceration for Parents and Children. Ph.D. dissertation, University of Minnesota, Minneapolis, MI, USA.

Williams, Sheila, Jessie Anderson, Rob McGee, and Phil A. Silva. 1990. Risk factors for behavioral and emotional disorder in preadolescent children. Journal of Academy of Child and Adolescent Psychiatry 29: 413-19. [CrossRef] [PubMed]

Yule, Amy, Timothy E. Wilens, Mary Kate Martelon, Andrew Simon, and Joseph Biederman. 2013. Does exposure to parental substance use disorders increase substance use disorder risk in offspring? A 5-year follow-upstudy. The American Journal of Addictions 22: 460-65. [CrossRef] [PubMed]

(C) 2017 by the author. Licensee MDPI, Basel, Switzerland. This article is an open access article distributed under the terms and conditions of the Creative Commons Attribution (CC BY) license (http://creativecommons.org/licenses/by/4.0/). 